\title{
Fabrication of novel polymer-modified graphene-based electrochemical sensor for the determination of mercury and lead ions in water and biological samples
}

\author{
Chenthattil Raril and Jamballi G. Manjunatha* (1)
}

\begin{abstract}
Background: This paper presents the application of polyglycine-modified graphene paste electrode (PGMGPE) for the electrochemical detection of $\mathrm{Hg}(\mathrm{II})$ and $\mathrm{Pb}$ (II) ions in the water and biological samples.

Method: The developed electrode was characterized by field emission scanning electron microscopy. Electrochemical techniques such as cyclic voltammetry and differential pulse voltammetry were used to study the behavior of metal ions.

Results: The modification process improves the electrochemical behavior of heavy metal ions. The peak current varied linearly with the increase of the concentration leading to a detection limit of $6.6 \mu \mathrm{M}(\mathrm{Hg}(\mathrm{II}))$ and $0.8 \mu \mathrm{M}(\mathrm{Pb}$ (II)), respectively.

Conclusion: The developed electrode exhibits good sensitivity, selectivity, stability, and lower detection limit, and was successfully applied to the determination of heavy metal ions in water and biological samples with a good recovery range.
\end{abstract}

Keywords: $\mathrm{HgCl}_{2}, \mathrm{PbCl}_{2}$, Graphene, Glycine, Cyclic voltammetry, Blood serum, Water sample

\section{Introduction}

Heavy metal ions are one of the most hazardous pollutants in the environment and are highly toxic. Mainly, environmental pollution by heavy metals is attributed to lead, cadmium, mercury, and copper. Trace heavy metal elements are fundamental to living organisms for a normal and healthy life. Excessive level of heavy metal pollution in the environment could cause harm (Li et al. 2013; Guascito et al. 2008). The accumulation of heavy metal ions in the human body can cause diseases in the central nervous system, liver, kidney, and skin (Bodo et al. 2010). So, it has become an important task to develop a cost-effective and sensitive method for the detection of heavy metal ions. Currently, various techniques have been reported for the detection of heavy metals such as atomic absorption spectroscopy (Liu et al. 2005) and fluorescence spectrometry (Liu

\footnotetext{
* Correspondence: manju1853@gmail.com

Department of Chemistry, FMKMC College, Mangalore University Constituent College, Madikeri, Karnataka, India
}

et al. 2005). However, these methods are expensive and time-consuming. In contrast, electrochemical methods (Huang and He 2013; Gherasim et al. 2014; Huakun et al. 2016; Sathish Reddy et al. 2012a, b, 2018; Gururaj et al., 2018; Ongera Gilbert et al. 2009; Mahanthesha et al. 2010; Liu et al, 2012) have advantages over the above techniques such as being inexpensive, highly sensitive, and easy to use. Cyclic voltammetry (CV) and differential pulse voltammetry (DPV) are sensitive techniques for the detection of heavy metals in water.

Many approaches are used for the modification of the working electrode surface by chemicals such as thiolamine (Fu et al. 2013), polymers (Ahuja et al. 2007; McQuade et al., 2000; Mohadesi and Taher, 2007), and monomolecular ligands (Canpolat et al. 2007; Zheng et al. 2006; Zhang et al., 2002; Anandhakumar and Mathiyarasu 2013). Graphene shows a wide application as an electrode material, because it shows very high electrical conductivity, good mechanical properties, fast 
electron transfer rate, and a high specific surface area (Zhao et al. 2012). Graphene has a thin layer of $\mathrm{sp}^{2}$ bonded carbon atoms, stacked in a two-dimensional (2D) honeycomb lattice and belongs to the class of carbon nanomaterials (Konios et al. 2014). It is widely used in various fields including electronics, biological, medicine, energy storage, and catalysis (Gupta et al. 2016, Gupta et al. 2012; Khani et al. 2010; Jain et al. 2006, Jain et al. 1997; Wei et al. 2019; Beitollahi et al. 2014, 2017; Tajik et al. 2014; Movlaee et al. 2017).

In this paper we report the development of an electrochemical sensor based on polyglycine-modified graphene for the determination of $\mathrm{Hg}^{2+}$ and $\mathrm{Pb}^{2+}$ ions using the cyclic voltammetry $(\mathrm{CV})$ technique. The electrochemical behavior of the heavy metal ions was studied at the bare and modified electrode and it was shown that the redox signal of these two heavy metal ions was promoted by the modified electrode. The developed sensor is less expensive and shows a wide linear response range with low detection limit, good stability, and reproducibility. Short or limited shelf life is the main disadvantage of the developed sensor. To our best knowledge, no research has been conducted to study the heavy metal ion detection at polyglycine-modified graphene paste electrode.

\section{Experimental}

\section{Chemicals and reagents}

Graphene was obtained from Tokyo Chemical Industries. Glycine and silicone oil were obtained from Nice Chemical Pvt Ltd., Kerala. Disodium hydrogen phosphate and sodium dihydrogen phosphate were obtained from Himedia. Phosphate buffer solution (PBS) $0.1 \mathrm{M}$ was prepared by mixing $0.1 \mathrm{M}$ disodium and sodium dihydrogen phosphate, and diluted with water and used as a supporting electrolyte. The $\mathrm{pH}$ was adjusted by adding an acid solution. Other chemicals such as $\mathrm{HgCl}_{2}$ and $\mathrm{PbCl}_{2}$ were of analytical grade and used as received from the manufacturers. Distilled water was used for the preparation of all the solutions.

\section{Instrumentation}

CV and DPV were performed using the CHI6038E (CH Instrument, USA). The electrochemical cell comprises three electrodes; platinum wire and calomel electrode were used as a counter electrode and a reference electrode, respectively. The working electrode used in this study was a $3 \mathrm{~mm}$-diameter unmodified and modified graphene paste electrode. All the experiments were performed at room temperature. $\mathrm{pH}$ measurements were carried out using EQ-610 pH meter, which was calibrated before use. Field emission scanning electron microscopy (FESEM) was obtained using the instrument operating at $5.00 \mathrm{kV}$ (DST-PURSE
Laboratory, Mangalore University). All the peak currents were taken with background current.

\section{Preparation of bare paste electrode}

Bare graphene paste electrode was prepared by thoroughly mixing (15 min) 60:40 w/w\% of graphene and silicone oil in a small agate mortar. A portion of the paste was then packed into the tip of the electrode of 3 $\mathrm{mm}$ diameter. Before each experiment, the surface was smoothed with a tissue paper until a shiny and clean electrode surface was obtained.

\section{Results and discussion}

\section{Preparation of modified paste electrode}

The electropolymerization technique was used for the preparation of PGMGPE. The prepared BGPE was kept in the electrochemical cell containing glycine $\left(1 \times 10^{-3} \mathrm{M}\right)$ and $0.1 \mathrm{M}$ PBS of $\mathrm{pH}$ 5.7. The electropolymerization was carried out at the potential window from $0.5 \mathrm{~V}$ to $1.5 \mathrm{~V}$ at a scan rate of $0.1 \mathrm{~V} / \mathrm{s}$ (Fig. 1). The electropolymerization cycles were optimized as ten cycles, because after ten cycles the peak current started decreasing (data not shown). Therefore, ten cycles were chosen as the optimum scan number.

\section{Structural features of BGPE and PGMGPE}

The morphological characterization of BGPE and PGMGPE was examined by FESEM. Figure 2a shows the morphology of BGPE, and Fig. 2b shows the morphology of PGMGPE. It was seen that BGPE contained flakes of graphene with an irregular surface and it was covered with a polymer film after electropolymerization with glycine, confirming that the BGPE was modified with a polymer film.

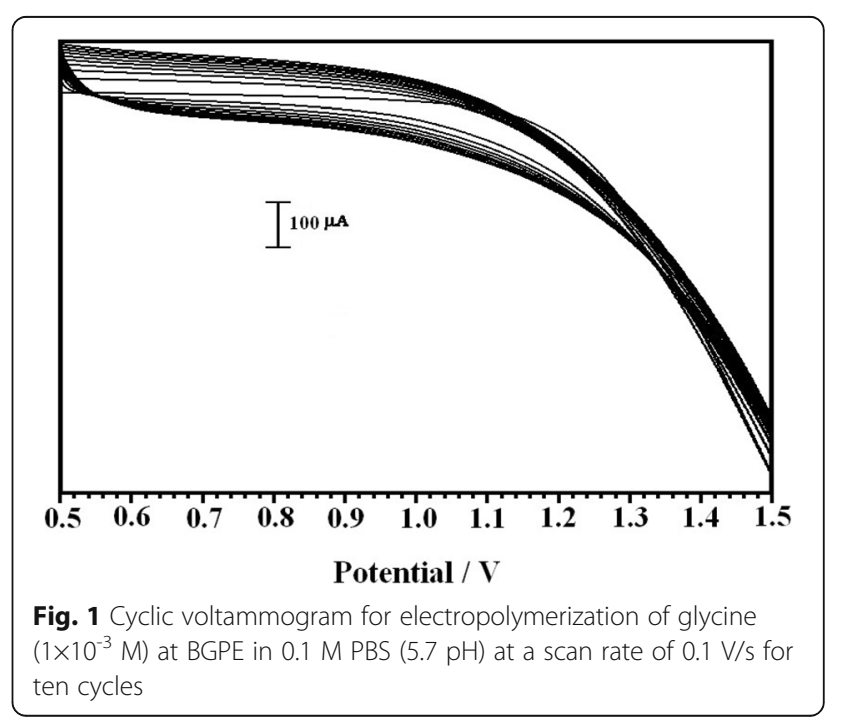




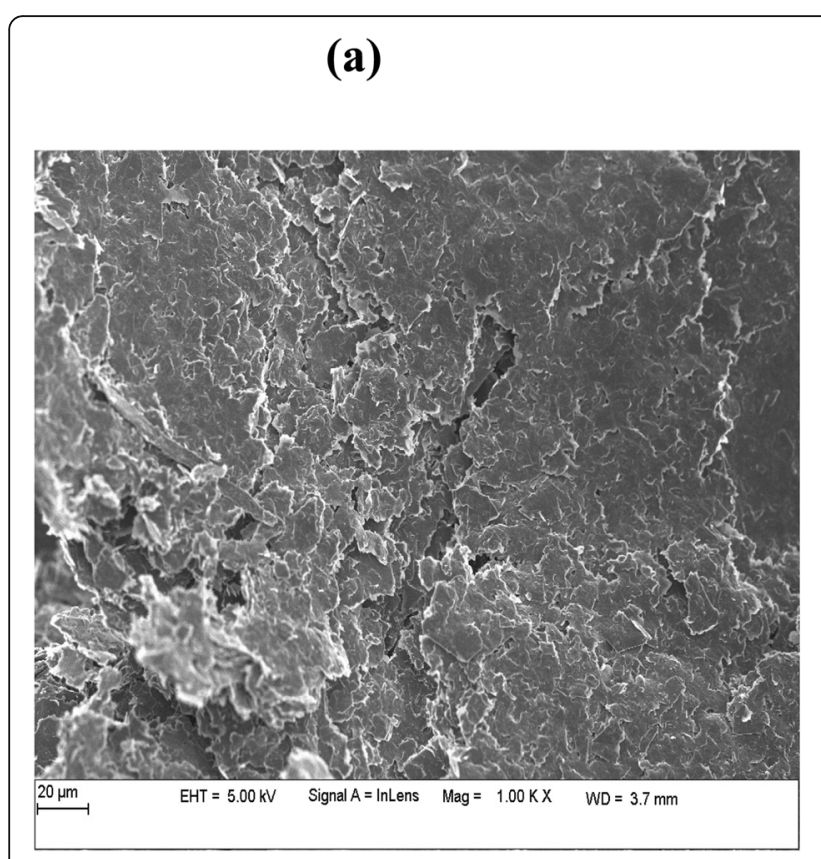

(b)

Fig. 2 FESEM image of $\mathbf{a} B G P E$ and $\mathbf{b} P G M G P E$

\section{Electrochemical behavior of $\mathrm{K}_{4}\left[\mathrm{Fe}(\mathrm{CN})_{6}\right]$}

The electrochemical behavior of $\mathrm{K}_{4}\left[\mathrm{Fe}(\mathrm{CN})_{6}\right]$ was studied at the bare and modified electrode in $0.1 \mathrm{M} \mathrm{KCl}$ as a supporting electrolyte with $1 \mathrm{mM} \mathrm{K}_{4}\left[\mathrm{Fe}(\mathrm{CN})_{6}\right]$. Figure 3 shows the cyclic voltammogram of $\mathrm{K}_{4}\left[\mathrm{Fe}(\mathrm{CN})_{6}\right]$ at the bare (curve b) and the modified electrode (curve a). The modified electrode shows well-defined oxidation and reduction peaks at $0.248 \mathrm{~V}$ and $0.183 \mathrm{~V}$. The modified electrode showed an enhancement in the peak current with increase in electron transfer kinetics. This confirmed that the electrode surface property was significantly changed and showed the good electrocatalytic activity of modified electrode toward $\mathrm{K}_{4}\left[\mathrm{Fe}(\mathrm{CN})_{6}\right]$. The surface area can be estimated by the Randles-Sevcik equation:

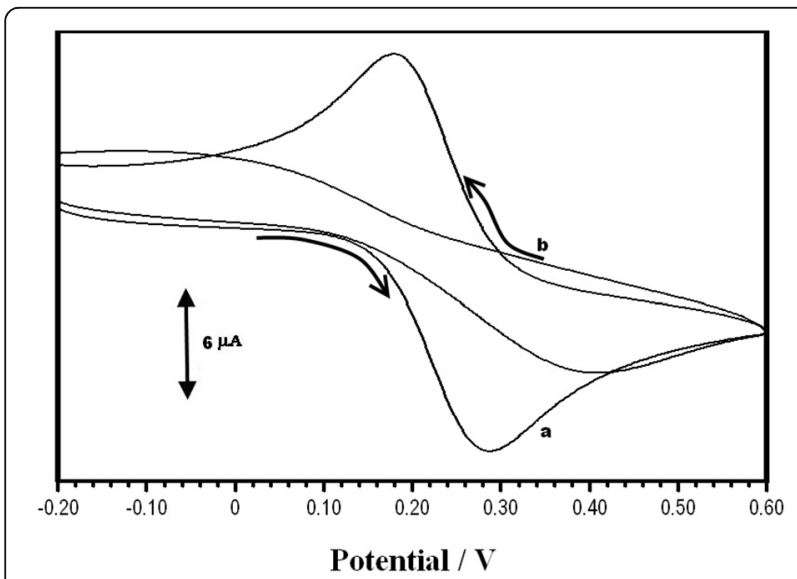

Fig. 3 Cyclic voltammograms for the electrochemical response of $\mathrm{K}_{4}\left[\mathrm{Fe}(\mathrm{CN})_{6}\right]$ at the bare (curve b) and modified electrode (curve a) in $0.1 \mathrm{M} \mathrm{KCl}$ containing $1 \mathrm{mM} \mathrm{K}_{4}\left[\mathrm{Fe}(\mathrm{CN})_{6}\right]$ at a scan rate of $0.1 \mathrm{~V} / \mathrm{s}$

$$
I_{\mathrm{p}}=2.69 \times 10^{5} n^{3 / 2} A D_{0}{ }^{1 / 2} C_{0} v^{1 / 2}
$$

where $I_{\mathrm{p}}$ is the peak current in $A, C_{0}$ is the concentration of the electroactive species $\left(\mathrm{mol} / \mathrm{cm}^{3}\right), n$ is the number of electrons involved in the reaction, $D_{0}$ is the diffusion coefficient in $\mathrm{cm}^{2} / \mathrm{s}, v$ is the scan rate $(\mathrm{V} / \mathrm{s})$, and $A$ is the electroactive surface area $\left(\mathrm{cm}^{2}\right)$. For the modified electrode, the surface area is maximum $(0.03$ $\left.\mathrm{cm}^{2}\right)$ as compared to the bare electrode $\left(0.02 \mathrm{~cm}^{2}\right)$.

\section{Electrochemical investigation}

$\mathrm{CV}$ was investigated to check the electrode behavior before and after the modification. A small anodic and cathodic peak was observed on the BGPE (Fig. 4 (curve b)) in $0.1 \mathrm{M}$ $\mathrm{PBS}$ at $\mathrm{pH} 4.5$ in the potential window from $-0.10 \mathrm{~V}$ to 0.50 $\mathrm{V}$ for $\mathrm{HgCl}_{2}$. It showed that the electron transfer between the electrode and analyte $\left(\mathrm{HgCl}_{2}\right)$ in the solution occurred very slowly. Two reduction peaks were observed for $\mathrm{HgCl}_{2}$ at $0.119 \mathrm{~V}$ and $0.0407 \mathrm{~V}$, which were shifted to $0.133 \mathrm{~V}$ and $0.015 \mathrm{~V}$ at PGMGPE (Fig. 4 (curve a)) with an increase in both peak currents. This result shows that the electron transfer rate increased at PGMGPE. The mechanism for the reduction process is explained as follows:

$$
\begin{aligned}
& \mathrm{Hg}^{2+}+\mathrm{e} \rightarrow \mathrm{Hg}^{+} \\
& \mathrm{Hg}^{+}+\mathrm{e} \rightarrow \mathrm{Hg}^{0}
\end{aligned}
$$

Figure 5 shows the $\mathrm{CV}$ response of $\mathrm{PbCl}_{2}$ at the BGPE (curve b) and PGMGPE (curve a). A small 


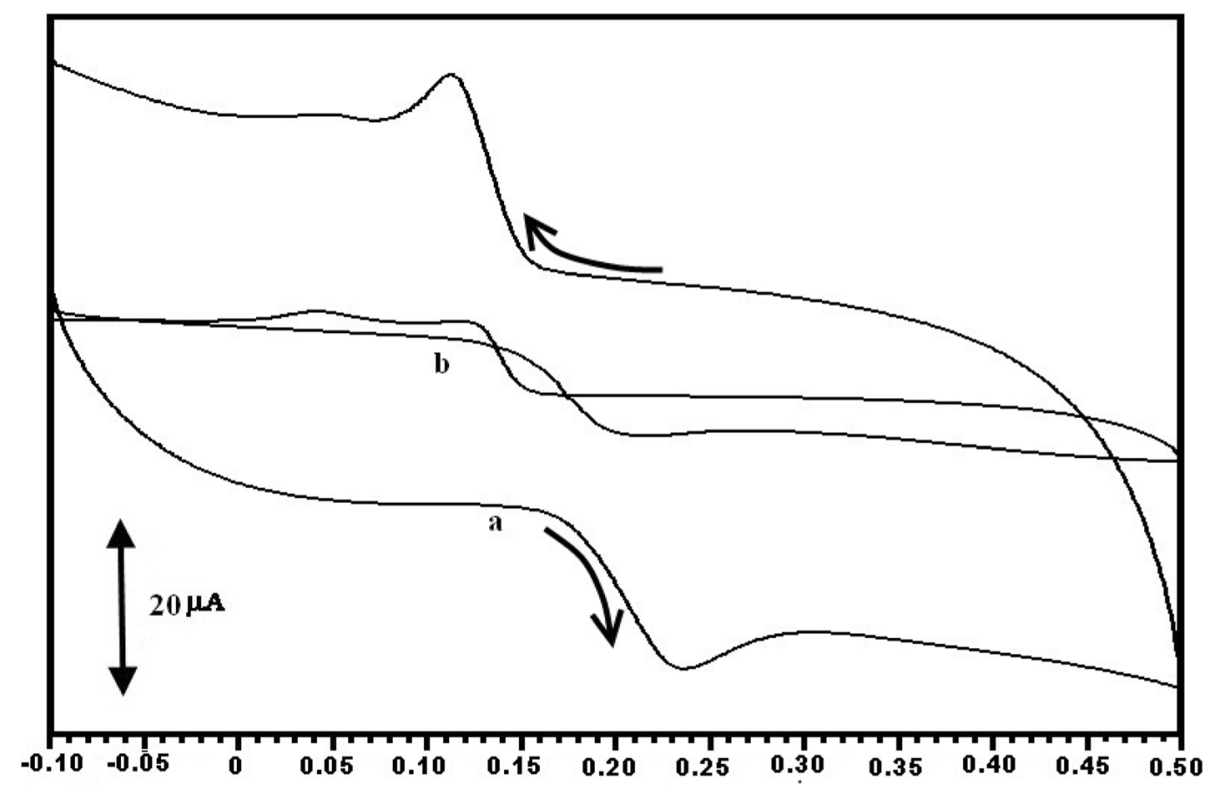

\section{Potential / V}

Fig. 4 Cyclic voltammograms of $1 \mathrm{mM} \mathrm{HgCl}_{2}$ at BGPE (curve b) and PGMGPE (curve a) in $0.1 \mathrm{M} \mathrm{PBS} \mathrm{(pH} \mathrm{4.5)} \mathrm{at} \mathrm{a} \mathrm{scan} \mathrm{rate} \mathrm{of} 0.1 \mathrm{~V} / \mathrm{s}$

current response observed at the bare electrode showed the difficulty of the metal ions to be adsorbed on to the bare electrode. On the other hand, for the modified electrode, the peak current value was larger than that obtained for the bare electrode, showing that the glycine film could be as an excellent supporting material for the heavy metal sensor. The polyglycine film exhibited a strong adsorption power of the heavy metal ions, and hence improved the surface sensitivity of the electrode.

\section{Effect of varying $\mathrm{pH}$}

The $\mathrm{pH}$ for the determination of heavy metal ion has a significant effect on the voltammetric behavior. The effect of different $\mathrm{pH}$ values on the electrochemical response was studied in the $\mathrm{pH}$ range from 3.5 to 5.5. Figure $6 \mathrm{a}$ shows the cyclic voltammograms for $\mathrm{HgCl}_{2}$ at different $\mathrm{pH}$ values at a scan rate of $0.1 \mathrm{~V} / \mathrm{s}$ in the potential window from -0.10 to $0.50 \mathrm{~V}$. It was observed that the peak current for $\mathrm{HgCl}_{2}$ is maximum at $\mathrm{pH}$ 4.5. The decrease in the

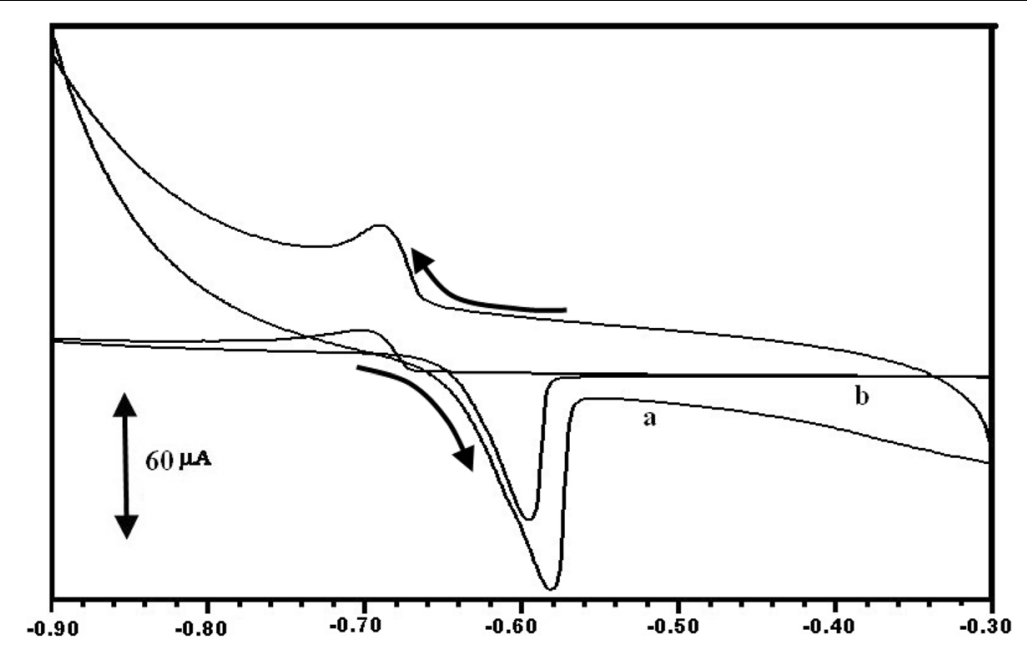

Potential / V

Fig. 5 Cyclic voltammograms of $1 \mathrm{mM} \mathrm{PbCl}_{2}$ at BGPE (curve b) and PGMGPE (curve a) in $0.1 \mathrm{M} \mathrm{PBS}$ (pH 4.5) at a scan rate of $0.1 \mathrm{~V} / \mathrm{s}$ 


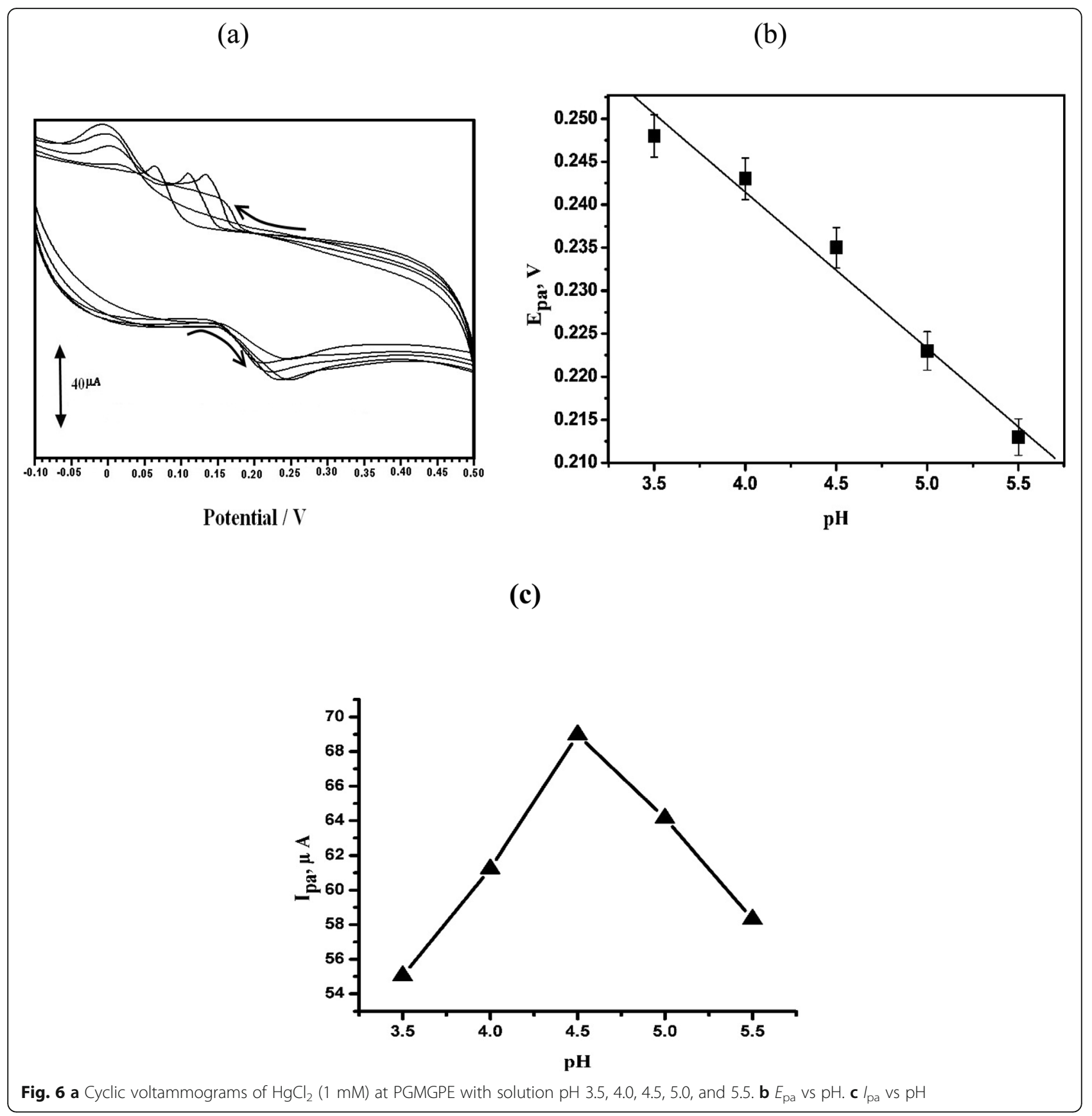

current at $\mathrm{pH}$ lower than 4.5 is explained by the protonation process, which affects the hydrophilic character of the electrode. The decrease in the current at $\mathrm{pH}$ higher than 4.5 is attributed to the hydrolysis of $\mathrm{Hg}^{2+}$ ions. Therefore, all electrochemical measurements were carried out in 0.1 M PBS at an optimal $\mathrm{pH}$ 4.5. The linear shift in the oxidation potential is describes by the equation: $E_{\mathrm{pa}}(\mathrm{V})=$ 313.4-18 pH, with the correlation coefficient of 0.99 (Fig. 6b). The relation between the peak current and $\mathrm{pH}$ is shown in Fig. 6c.
Effect of scan rate

To study the nature of the electron process, the effect of various scan rates was evaluated in $0.1 \mathrm{M}$ PBS of $\mathrm{pH} 4.5$ from 0.1 to $0.275 \mathrm{~V} / \mathrm{s}$. Figure $7 \mathrm{a}$ shows the effect of scan rate on the peak current for $\mathrm{HgCl}_{2}$. It was observed that as the scan rate increased, the peak current also increased, and the potential was shifted to the more positive side. It was observed that the peak potential was shifted from $0.235 \mathrm{~V}$ to $0.270 \mathrm{~V}$. The linear relationship between the peak current and scan rate is described by the 


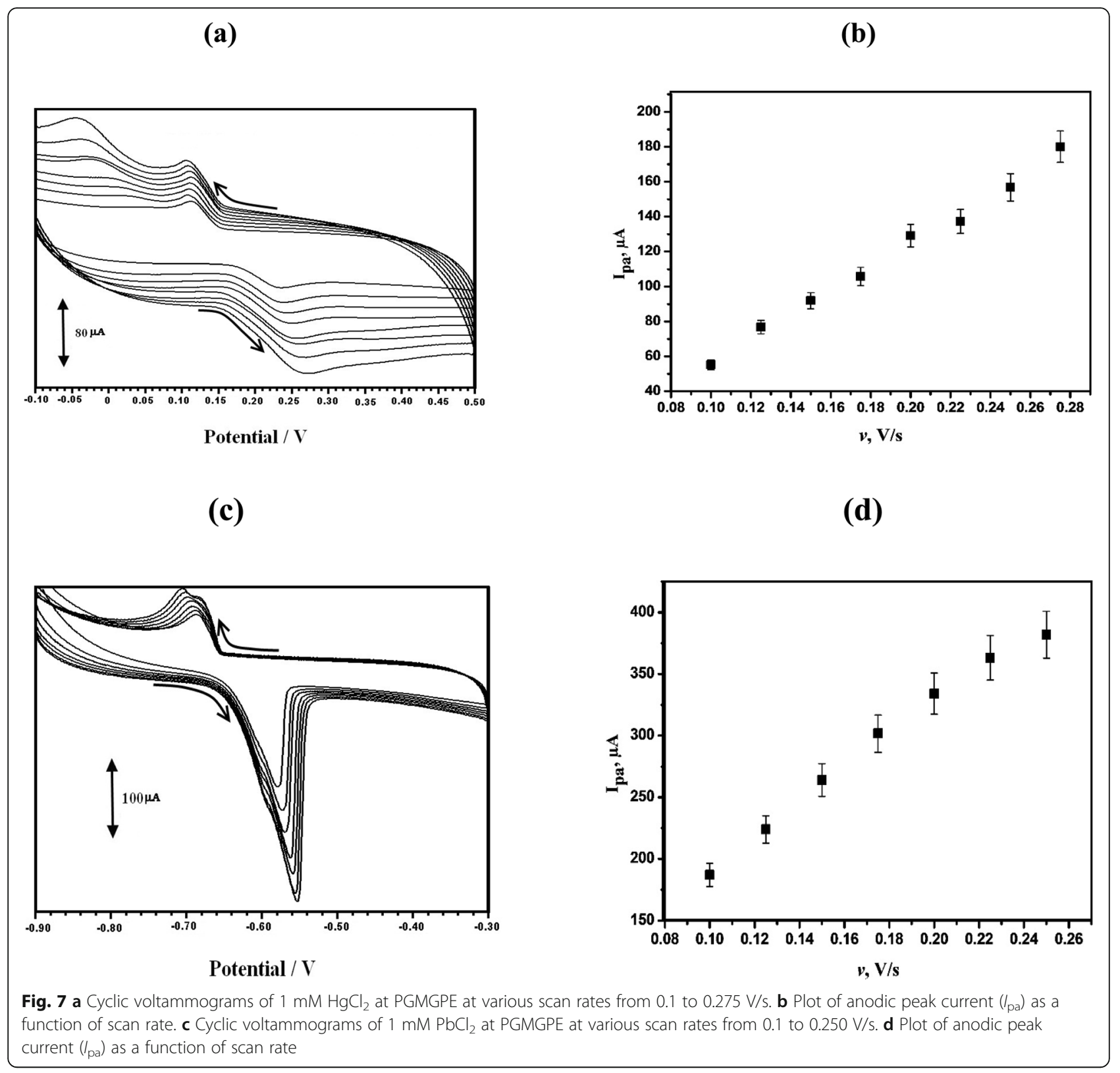

following equation: $I_{\mathrm{pa}}(\mu \mathrm{A})=-11.34+682.57 v(\mathrm{~V} /$ s), with the correlation coefficient of 0.99 (Fig. 7b). It indicates that the electrode process is adsorption controlled.

Figure 7c shows the cyclic voltammograms for $\mathrm{PbCl}_{2}$ for different scan rates. It was seen that as the scan rate increased, the peak current also increased and peak potential was shifted toward less negative from 0.1 to 0.250 $\mathrm{V} / \mathrm{s}$ in $0.1 \mathrm{M}$ PBS having $\mathrm{pH} 4.5$. There is a linear relationship between the peak current and scan rate as observed in the linear regression equation of $I_{\mathrm{pa}}(\mu \mathrm{A})=$ $60.17+1334.4 v(\mathrm{~V} / \mathrm{s})$, with the correlation coefficient of 0.994 (Fig. $7 \mathrm{~d}$ ), indicating that the electrode process is adsorption controlled.

\section{Effect of concentration}

The effect of concentrations on the peak current of $\mathrm{HgCl}_{2}$ and $\mathrm{PbCl}_{2}$ at PGMGPE was studied using $\mathrm{CV}$ in $0.1 \mathrm{M}$ PBS, $4.5 \mathrm{pH}$, at the scan rate of $0.1 \mathrm{~V} / \mathrm{s}$. It was seen that as the concentration increased, the peak current also increased in the range of $1.5 \times 10^{-4}$ to $1.5 \times 10^{-3} \mathrm{M}$ for $\mathrm{HgCl}_{2}$. Two linear ranges were observed for $\mathrm{PbCl}_{2}$ as follows: $2 \times 10^{-4}$ to $4.5 \times 10^{-4}$ $\mathrm{M}$ and $5 \times 10^{-4}$ to $1.2 \times 10^{-3} \mathrm{M}$. A linear relationship was observed between the concentration and peak current in the linear equation: $I_{\mathrm{pa}}(\mathrm{A})=3.59 \times 10^{-4}+0.013\left[\mathrm{HgCl}_{2}\right](\mathrm{M})$ with the correlation coefficient of 0.993 (Fig. 8a), and $I_{\mathrm{pa}}(\mathrm{A})=$ $4.44 \times 10^{-5}+0.149\left[\mathrm{PbCl}_{2}\right](\mathrm{M})$ with the correlation coefficient of 0.996 (Fig. 8b). The detection limit was calculated by the following equation: $\mathrm{DL}=3 S / N$ (Manjunatha, 2018a, b; 
(a)

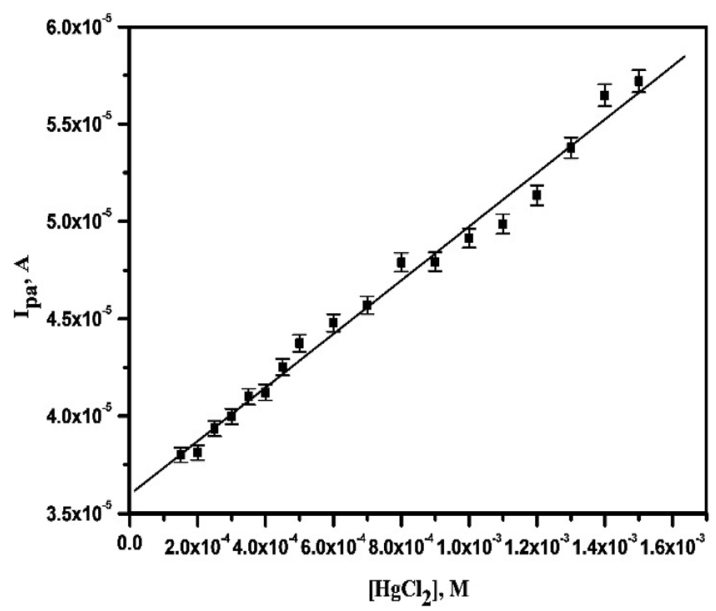

(b)

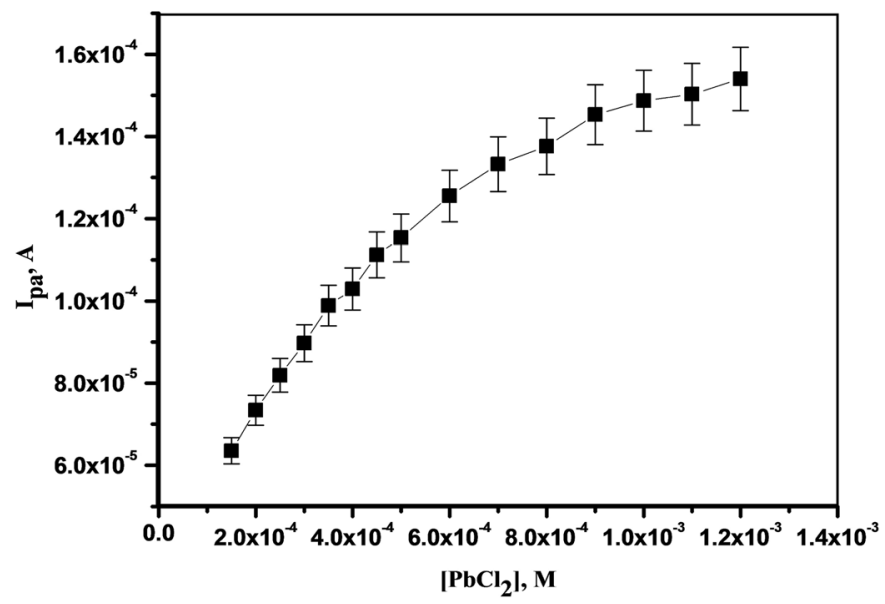

Fig. 8 a Plot of the oxidation peak current as a function of concentration of $\mathrm{HgCl}_{2}$ in $0.1 \mathrm{M} \mathrm{PBS}(\mathrm{pH} 4.5)$ at the scan rate of $0.1 \mathrm{~V} / \mathrm{s}$. $\mathbf{b}$ Plot of the oxidation peak current as a function of the concentration of $\mathrm{PbCl}_{2}$ in $0.1 \mathrm{M} \mathrm{PBS}(\mathrm{pH} 4.5)$ at the scan rate of $0.1 \mathrm{~V} / \mathrm{s}$

Manjunatha et al., 2018), where $S$ is the standard deviation for the blank (5 runs) and $N$ is the slope obtained from the calibration curve, and was obtained as $6.6 \mu \mathrm{M}\left(\mathrm{HgCl}_{2}\right)$ and $0.8 \mu \mathrm{M}\left(\mathrm{PbCl}_{2}\right)$. The limit of detection is used to describe the smallest concentration of an analyte that can be reliably measured by an analytical procedure. The comparison of the detection limit of the present work with other works is shown in Table 1 (Lu et al. 2015; Cesarino et al. 2008; MartinezHuitle et al. 2010; Wang et al. 2011; Othman et al. 2016).

\section{Simultaneous study}

The possible interference of the two metal ions was evaluated by simultaneous analysis of $\mathrm{HgCl}_{2}$ and $\mathrm{PbCl}_{2}$. Figure $9 \mathrm{a}$ shows the CV response of $\mathrm{HgCl}_{2}(1 \mathrm{mM})$ (b) and $\mathrm{PbCl}_{2}(1$ $\mathrm{mM}$ ) (a) recorded from -0.7 to $0.3 \mathrm{~V}$ at $0.1 \mathrm{~V} / \mathrm{s}$ in $0.1 \mathrm{M}$ PBS ( $\mathrm{pH} 4.5$ ). Figure 9b shows the DPV response of $\mathrm{HgCl}_{2}$ (1 mM) (b) and $\mathrm{PbCl}_{2}(1 \mathrm{mM})$ (a) recorded from -0.7 to 0.3 $\mathrm{V}$ at $0.1 \mathrm{~V} / \mathrm{s}$ in $0.1 \mathrm{M} \mathrm{PBS}(\mathrm{pH} 4.5)$. The clean separation of the two potential peaks shows the possibility of the simultaneous determination of $\mathrm{HgCl}_{2}$ and $\mathrm{PbCl}_{2}$. At an identical time, the interference study was also carried in the sample of the mixture containing $\mathrm{HgCl}_{2}$ and $\mathrm{PbCl}_{2}$. This was achieved by changing the concentration of one species and keeping the other constant and recording CVs. Figure 9c shows the CVs of $\mathrm{HgCl}_{2}$ with different concentrations (1000 $\mu \mathrm{M}-1100 \mu \mathrm{M})$, while keeping the concentration of $\mathrm{PbCl}_{2}$ as $1000 \mu \mathrm{M}$. There was no change in the peak current for $\mathrm{PbCl}_{2}$, while the peak current for $\mathrm{HgCl}_{2}$ increased linearly. In the next step, the concentration of $\mathrm{HgCl}_{2}$ was varied from $1000 \mu \mathrm{M}-1180 \mu \mathrm{M}$ by keeping the concentration of $\mathrm{PbCl}_{2}(1000 \mu \mathrm{M})$ constant, and only the peak current of $\mathrm{HgCl}_{2}$ was increased linearly with the concentration (Fig. 9d). This result shows that $\mathrm{HgCl}_{2}$ and $\mathrm{PbCl}_{2}$ exist independently in their mixture of samples.

\section{Application of the modified electrode to the real sample Water sample}

The analytical performance of the prepared electrode in practical application was evaluated by measuring the activity of heavy metal ions in the real water sample. The sensor was tested and validated using the water sample in the potential -0.1 to $0.50 \mathrm{~V}$ with a scan rate of $0.1 \mathrm{~V} /$

Table 1 Comparison between the detection limit of the proposed method with other previously reported methods

\begin{tabular}{lllll}
\hline Electrode & Technique & Metal ion & Detection limit $(\mu \mathrm{M})$ & Reference \\
\hline Graphene-MnO 2 & LSV & $\mathrm{Hg}^{2+}$ & 2 & Lu et al. 2015 \\
CPE-SBA-15 & DPASV & $\mathrm{Hg}^{2+}$ & 0.4 & Cesarino et al. 2008 \\
GCE/CT & DPV & $\mathrm{Pb}^{2+}$ & 0.8 & Martinez-Huitle et al. 2010 \\
GCE/PANI & $\mathrm{PWV}$ & 0.1 & Wang et al. 2011 \\
Ag/DHE & $\mathrm{PV}$ & $\mathrm{Pb}^{2+}$ & 0.76 & Othman et al. 2016 \\
PGMGPE & $\mathrm{CV}$ & $\mathrm{Hg}^{2+}$ & 6.6 & Present work \\
& & $\mathrm{Pb}^{2+}$ & 0.8 & \\
\hline
\end{tabular}


(a)

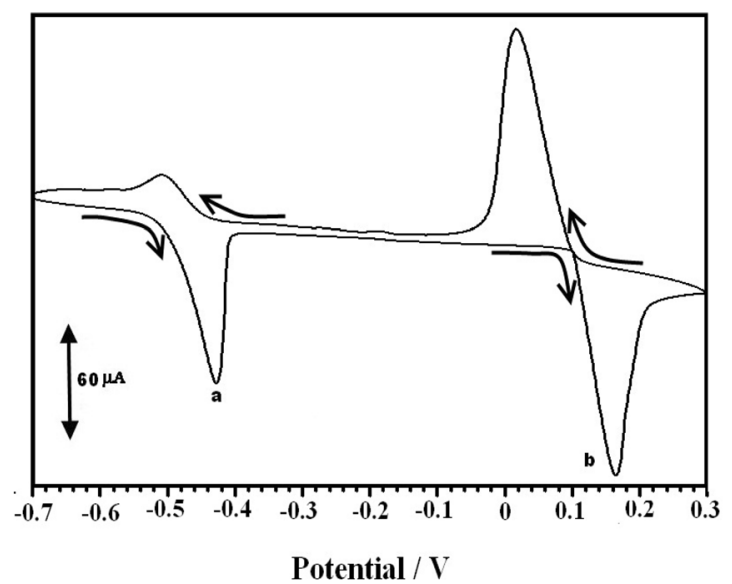

(c)

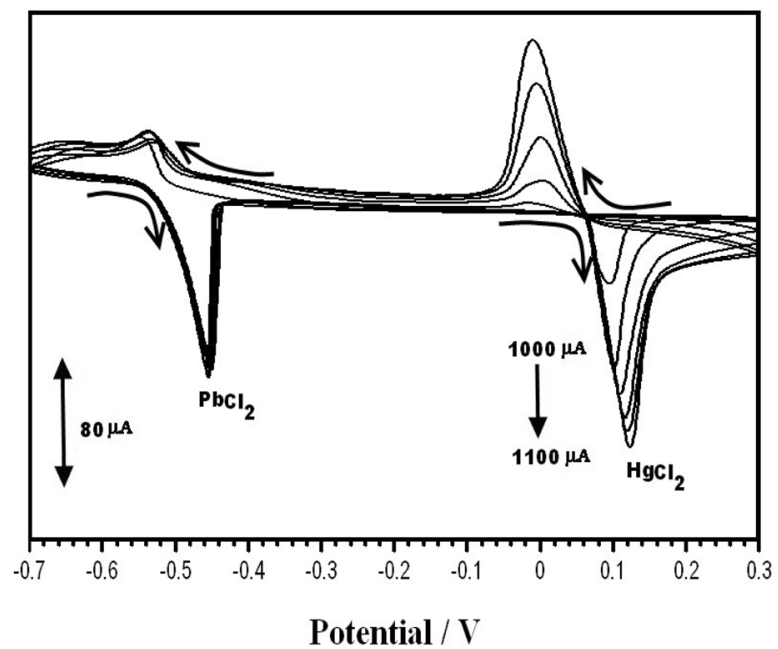

(b)

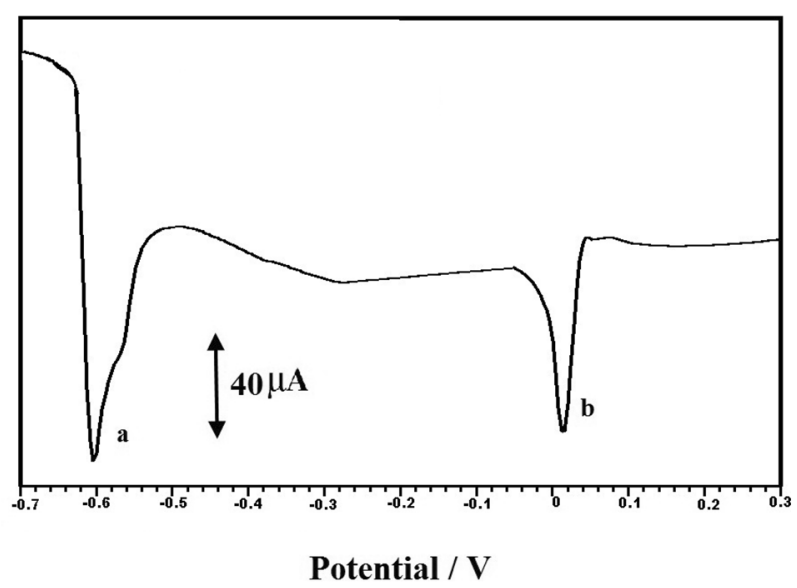

(d)

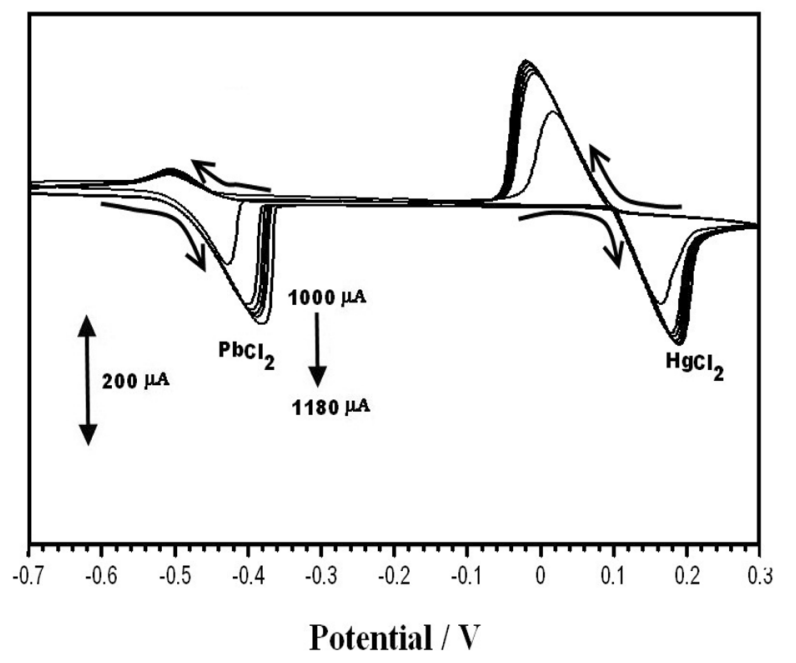

Fig. 9 a Cyclic voltammogram for the simultaneous analysis of $\mathrm{HgCl}_{2}$ and $\mathrm{PbCl}_{2}$ in $0.1 \mathrm{M} \mathrm{PBS}$ ( $\mathrm{pH} 4.5$ ) at a scan rate of $0.1 \mathrm{~V} / \mathrm{s}$. $\mathbf{b}$ Differential pulse voltammogram for the simultaneous analysis of $\mathrm{PbCl}_{2}$ and $\mathrm{HgCl}_{2}$ in $0.1 \mathrm{M} \mathrm{PBS}(\mathrm{pH} 4.5)$ at a scan rate of $0.05 \mathrm{~V} / \mathrm{s}$. c Cyclic voltammograms of different concentrations of $\mathrm{HgCl}_{2}(1000 \mu \mathrm{M}-1100 \mu \mathrm{M})$ and constant concentration of $\mathrm{PbCl}_{2}(1000 \mu \mathrm{M})$. d Cyclic voltammograms of different concentrations of $\mathrm{PbCl}_{2}(1000-1180 \mu \mathrm{M})$ and constant concentration of $\mathrm{HgCl}_{2}(1000 \mu \mathrm{M})$

s. In the groundwater sample, no signal was observed for the metal ions $\left(\mathrm{Hg}^{2+}\right.$ and $\left.\mathrm{Pb}^{2+}\right)$; however when different concentrations of $\mathrm{HgCl}_{2}$ and $\mathrm{PbCl}_{2}$ were added to the sample, current peaks were observed. Table 2 . shows the recovery ranges of $\mathrm{Hg}$ (II) and $\mathrm{Pb}$ (II). The obtained result shows that the developed electrode can have a suitable potential applicability in environmental monitoring.

\section{Biological sample}

Blood sample $(2 \mathrm{ml})$ was collected from the nearest district hospital. The serum was prepared by centrifuging the blood sample at $5000 \mathrm{rpm}$ for $5 \mathrm{~min}$. $1 \mathrm{ml}$ of the
Table 2 Result for the determination of $\mathrm{Hg}$ (II) and $\mathrm{Pb}$ (II) ions in groundwater

\begin{tabular}{llll}
\hline Sample & Added $(\mu \mathrm{M})$ & Found $(\mu \mathrm{M})$ & Recovery $(\%)$ \\
\hline $\mathrm{HgCl} 2$ & 150 & 147.75 & 98.5 \\
& 200 & 202 & 101 \\
$\mathrm{PbCl} 2$ & 40 & 39.1 & 97.84 \\
& 60 & 60.7 & 101.2 \\
\hline
\end{tabular}


Table 3 Determination of metal ions in the blood sample

\begin{tabular}{llll}
\hline Metal ion & Added $(\mu \mathrm{M})$ & Found $(\mu \mathrm{M})$ & Recovery $(\%)$ \\
\hline $\mathrm{Hg}^{2+}$ & 100 & 79.92 & 79.92 \\
& 1300 & 1280.63 & 98.51 \\
$\mathrm{~Pb}^{2+}$ & 80 & 69.31 & 86.63 \\
& 100 & 91.30 & 91.30 \\
\hline
\end{tabular}

sample was dissolved in $25 \mathrm{ml}$ of PBS and made up to the mark, and the experiment was carried out with the standard addition method. Table 3 shows the recovery ranges of metal ions in the blood sample.

\section{Sensor stability and reproducibility}

To investigate the stability of the sensor, the current behavior was studied before and after 25 cycles in $0.1 \mathrm{M}$ PBS, at $4.5 \mathrm{pH}$ and scan rate of $0.1 \mathrm{~V} / \mathrm{s}$. It was observed that even after 25 cycles, $85 \%$ of the initial current was retained, showing that the developed sensor had good stability. Reproducibility was studied with three successive removals of the electrode, keeping the solution same. It was observed that the relative standard deviation of $2.85 \%$ for the analyte indicated that the electrode had acceptable reproducibility.

\section{Novelty statement}

In this work, a novel electroanalytical method which showed good sensitivity and comparable with previous reports was presented. The method is based on the subduing of the peak current of the modifier due to the analyte in a modified carbon paste electrode.

\section{Conclusions}

In this study, an electrochemical sensor based on polyglycine-modified graphene paste electrode (PGMGPE) was developed for the quantification of trace $\mathrm{Pb}$ (II) and Hg (II). The developed electrode exhibits good sensitivity, selectivity, good stability, and lower detection limit. It was shown that the developed electrode provides an alternative strategy for the electrochemical determination of heavy metal ions. The modified electrode has been used to determine the $\mathrm{Pb}$ (II) and $\mathrm{Hg}$ (II) in water and blood samples. The result obtained in the analysis of $\mathrm{Hg}$ (II) and $\mathrm{Pb}$ (II) in water and blood samples had a good recovery, demonstrating the applicability of the method for real sample analysis.

\footnotetext{
Abbreviations

CV: Cyclic voltammetry; DPV: Differential pulse voltammetry; PBS: Phosphate buffer solution; PGMGPE: Polyglycine-modified graphene paste electrode; BGPE: Bare graphene paste electrode; FESEM: Field emission scanning electron microscopy; LSV: Linear sweep voltammetry; DPASV: Differential pulse anodic stripping voltammetry; SWV: Square wave voltammetry; $\mathrm{K}_{4}\left[\mathrm{Fe}(\mathrm{CN})_{6}\right]$ : Potassium ferrocyanide; CPE: Carbon paste electrode; CT/ GCE: Chitosan/glassy carbon electrode; GCE/PANI: Glassy carbon electrode/ polyaniline; Ag/DHE: Silver electrode/dithizone
}

\section{Acknowledgement}

We gratefully acknowledge the financial support from the VGST, Bangalore, under Research project. No. KSTePS/VGST-KFIST (L1) 2016-2017/GRD-559/ 2017-18/126/333, 21/11/2017.

\section{Authors' contributions}

This research work was planned and executed by CR and JGM. The experimental work and analysis were carried out by CR and JGM, and the manuscript was written by $C R$. All authors read and approved the final manuscript.

\section{Funding}

This research did not receive any specific grant from funding agencies.

\section{Availability of data and materials}

All the research data have been provided in the manuscript.

\section{Competing interests}

The authors declare that they have no competing interests.

Received: 1 July 2019 Accepted: 25 October 2019

Published online: 10 January 2020

\section{References}

Ahuja T, Mir IA, Kumar D, Rajesh. Biomolecular immobilization on conducting polymers for biosensing applications. Biomaterials. 2007;28:791-05.

Anandhakumar S, Mathiyarasu J. Detection of lead (II) using an glassy carbon electrode modified with nafion, carbon nanotubes and benzo-18-crown-6. Microchim. Acta. 2013;180:1065-71.

Beitollahi H, Dehghannoudeh GM, Moghaddam H, Forootanfar H. A sensitive electrochemical DNA biosensor for anticancer drug topotecan based on graphene carbon paste electrode. J. Electrochem. Soc. 2017;164:H812-7.

Beitollahi H, Tajik S, Biparva P. Electrochemical determination of sulfite and phenol using a carbon paste electrode modified with ionic liquids and graphene nanosheets: Application to determination of sulfite and phenol in real samples. Measurement. 2014;56:170-7.

Bodo M, Balloni S, Lumare E, Bacci M, Calvitti M, Dell'Omo M, Murgia N, Marinucci L. Effects of sub-toxic cadmium concentrations on bone gene expression program: results of an in vitro study. Toxicol. in Vitro. 2010;24:1670-80.

Canpolat E, Sar E, Coskun N, Cankurtaran H. Determination of trace amounts of copper in tap water samples with a calix [4] arene modified carbon paste electrode by differential pulse anodic stripping voltammetry. Electroanal. 2007;19:1109-15.

Cesarino I, Marino G, do Rosario Matos J, Gomes Cavalheiro ET. Evaluation of a carbon paste electrode modified with organofunctionalised SBA-15 nanostructured silica in the simultaneous determination of divalent lead, copper and mercury ions. Talanta. 2008;75:15-21.

Fu X, Wu J, Li J, Xie C, Liu Y, Zhong Y, Liu J. Electrochemical determination of trace copper (II) with enhanced sensitivity and selectivity by gold nanoparticle/ single-wall carbon nanotube hybrids containing three-dimensional L-cysteine molecular adapters. Sens. Actuators B. 2013;182:382-9.

Gherasim CV, Krivcik J, Mikulasek P. Investigation of batch electrodialysis process for removal of lead ions from aqueous solutions. Chem. Eng. J. 2014;256:324-34.

Gilbert O, Kumara Swamy BE, Chandra U, Sherigara BS. Simultaneous detection of dopamine and ascorbic acid using polyglycine modified carbon paste electrode: A cyclic voltammetric study. J. Electroanal. Chem. 2009;636:80-5.

Guascito MR, Malitesta C, Mazzotta E, Turco A. Inhibitive determination of metal ions by an amperometric glucose oxidase biosensor: study of the effect of hydrogen peroxide decomposition. Sens. Actuators B: Chem. 2008;131:394-02.

Gupta VK, Moradi O, Tyagi I, Agarwal S, Sadegh H, Shahryari-Ghoshekandi R, Makhlouf ASH, Goodarzi M, Garshasbi A. Study on the removal of heavy metal ions from industry waste by carbon nanotubes: effect of the surface modification: a review. Crit. Rev. Env. Sci. Tec. 2016;46:93-118.

Gupta VK, Yola ML, Atar N, Ustundag Z, Solak AO. A novel sensitive Cu (II) and Cd (II) nanosensor platform: graphene oxide terminated p-aminophenyl modified glassy carbon surface. Electrochim. Acta. 2012;112:541-8.

Gururaj KJ, Kumara Swamy BE, Ramirez HNG, Ekanthappa MT, Flores-Moreno R. Quantum chemical and electrochemical studies of lysine modified carbon paste electrode surfaces for sensing dopamine. New J. Chem. 2018;42:4501-6.

Huakun X, Jingkun X, Xiaofei Z, Xuemin D, Limin L, Yinxiu Z, Youshan Z, Wenmin $W$. A new electrochemical sensor based on carboimidazole grafted reduced 
graphene oxide for simultaneous detection of $\mathrm{Hg}^{2+}$ and $\mathrm{Pb}^{2+}$. J. Electroanal. Chem. 2016;782:250-5.

Huang CC, He JC. Electrosorptive removal of copper ions from wastewater by using ordered mesoporous carbon electrodes. Chem. Eng. J. 2013;221:469-75.

Jain AK, Gupta VK, Singh LP. Macrocycle based membrane sensors for the determination of cobalt (II) ions. Analyst. 1997;122:583-6.

Jain AK, Gupta VK, Singh LP, Raisoni JR. A comparative study of Pb2+ selective sensors based on derivatized tetrapyrazole and calix [4] arene receptors. Electrochim. Acta. 2006;51:2547-53.

Khani H, Rofouei MK, Arab P, Gupta VK, Vafaei Z. Multi-walled carbon nanotubes-ionic liquid-carbon paste electrode as a super selectivity sensor: application to potentiometric monitoring of mercury ion (II). J. hazard. mater. 2010;183:402-9.

Konios D, Stylianakis MM, Stratakis E, Kymakis E. Dispersion behaviour of graphene oxide and reduced graphene oxide. J. Colloid Interface Sci. 2014; 430:108-12.

Li M, Gou H, Al-Ogaidi I, Wu N. Nanostructured sensors for detection of heavy metals: a review. ACS Sustain. Chem. Eng. 2013;1:713-23.

Liu JM, Lin LP, Wang XX, Lin SQ, Cai WL, Zhang LH, Zheng ZY. Highly selective and sensitive detection of $\mathrm{Cu}(\mathrm{II})$ with lysine enhancing bovine serum albumin modified-carbon dots fluorescent probe. Analyst. 2012:137:2637-42.

Liu YW, Chang XJ, Yang D, Guo Y, Meng SM. Highly selective determination of inorganic mercury (II) after preconcentration with $\mathrm{Hg}$ (II)-imprinted diazoaminobenzene- vinylpyridine copolymers. Anal. Chim. Acta. 2005;538:85-91.

Lu J, Zhang X, Zhang X, Liu N, Li H, Yu Z, Yan X. Electrochemical sensor for mercuric chloride based on graphene- $\mathrm{MnO}_{2}$ composite as recognition element. Electrochim Acta. 2015;174:221-9.

Mahanthesha KR, Kumara Swamy BE, Vasantakumar Pai K, Chandra U, Sherigara BS. Cyclic Voltammetric Investigations of Dopamine at Alizarin Modified Carbon Paste Electrode, Int. J. Electrochem. Sci. 2010;5:1962-71.

Manjunatha JG. A novel voltammetric method for the enhanced detection of the food additive tartrazine using an electrochemical sensor. Heliyon. 2018a;4. https://doi.org/10.1016/j.heliyon.2018.e00986.

Manjunatha JG. A novel poly (glycine) biosensor towards the detection of indigo carmine: A voltammetric study. J. food drug anal. 2018b;26:292-9.

Manjunatha JG, Deraman M, Basri NH, Talib IA. Fabrication of poly (Solid Red A) modified carbon nano tube paste electrode and its application for simultaneous determination of epinephrine, uric acid and ascorbic acid Arab. J. Chem. 2018;11:149-58.

Martinez-Huitle CA, Suely Fernandes N, Cerro-Lopez M, Quiroz MA. Determination of Trace Metals by Differential Pulse Voltammetry at Chitosan Modified Electrodes. Port. Electrochim. Acta. 2010;28:39-49.

McQuade DT, Pullen AE, Swager TM. Conjugated polymer-based chemical sensors. Chem. Rev. 2000;100:2537-74.

Mohadesi A, Taher MA. Overoxidized polypyrrole doped with 4,5-dihydroxy-3(psulfophenylazo)- 2,7-naphthalene disulfonic acid as a selective and regenerable film for the stripping detection of copper (II). Anal. Sci. 2007;23:969-74.

Movlaee K, Beitollahi H, Ganjali MR, Norouzi P. Strategy for Simultaneous Determination of Droxidopa, Acetaminophen and Tyrosine Using Carbon Paste Electrode Modified with Graphene and Ethyl 2-(4-ferrocenyl-[1,2,3] triazol-1-yl) Acetate. J. Electrochem. Soc. 2017;164:H407-12.

Othman MAF, Othman AA, Zuki HM. Dithizone modified silver electrode for the determination of metal ions in aqueous solution. Malaysian. J. Anal. Sci. 2016 20:197-04.

Reddy S, Kumara Swamy BE, Jayadevappa H. CuO nanoparticle sensor for the electrochemical determination of dopamine. Electrochim. Acta. 2012a;61:78-86.

Reddy S, Kumara Swamy BE, Ramakrishana S, Liumin H, Jayadevappa H. NiO Nanoparticles Based Carbon Paste as a Sensor for Detection of Dopamine. Int. J. Electrochem. Sci. 2018;13:5748-61.

Reddy S, Kumara Swamy BE, Vasan HN, Jayadevappa H. ZnO and ZnO/ polyglycine modified carbon paste electrode for electrochemical investigation of dopamine, Anal. Methods. 2012b;4:2778-83.

Tajik S, Taher MA, Beitollahi H. The first electrochemical sensor for determination of mangiferin based on an ionic liquid-graphene nanosheets paste electrode. Ionics. 2014;20:1155-61.

Wang Z, Liu E, Zhao X. Glassy carbon electrode modified by conductive polyaniline coating for determination of trace lead and cadmium ions in acetate buffer solution. Thin Solid Films. 2011;519:5285-9.

Wei $Y$, Zihua $H$, Junjie F, Xiaohua $H$. Sensitive electrochemical sensor based on poly(L-glutamic acid)/graphene oxide composite material for simultaneous detection of heavy metal ions. RSC Adv. 2019;9:17325-34.
Zhang Y, Lu X, Zhu K, Wanf Z, Kang J. Voltammtric detection of traces of copper using a carbon paste electrode modified with tetraphenylporphyrin. Anal. Lett. 2002;35:369-81.

Zhao B, Liu P, Jiang Y, Pan D, Tao H, Song J. Fang T. Xu W. supercapacitance performance of thermally reduced graphene oxide. J. power sources. 2012; 198:423-7.

Zheng H, Dong H, Yan Z, Wen L, Zhang S, Ye B. Determination of copper at a glassy carbon electrode modified with Langmuir-Blodgett film of p-tertbutylthiacalix [4] arene. Electroanal. 2006;18:2115-20.

\section{Publisher's Note}

Springer Nature remains neutral with regard to jurisdictional claims in published maps and institutional affiliations.

\section{Submit your manuscript to a SpringerOpen ${ }^{\circ}$ journal and benefit from:}

- Convenient online submission

- Rigorous peer review

- Open access: articles freely available online

High visibility within the field

- Retaining the copyright to your article

Submit your next manuscript at $\boldsymbol{\nabla}$ springeropen.com 